\title{
BMJ Open Perforated appendicitis in patients with schizophrenia: a retrospective cohort study
}

\author{
Yoshimasa Nishihira, ${ }^{1}$ Rita L McGill, ${ }^{2}$ Mitsuyo Kinjo ${ }^{3}$
}

To cite: Nishihira Y, McGill RL, Kinjo M. Perforated appendicitis in patients with schizophrenia: a retrospective cohort study. BMJ Open 2017;7:e017150. doi:10.1136/ bmjopen-2017-017150

- Prepublication history for this paper is available online. To view these files, please visit the journal online (http://dx.doi. org/10.1136/bmjopen-2017017150).

Received 25 April 2017 Revised 28 June 2017 Accepted 3 July 2017

\section{CrossMark}

${ }^{1}$ Department of Psychiatry, Okinawa Chubu Hospital, Uruma, Okinawa, Japan

${ }^{2}$ Division of Nephrology, University of Chicago, Chicago, Illinois, USA

${ }^{3}$ Division of Rheumatology, Department of Medicine, Okinawa Chubu Hospital, Uruma, Okinawa, Japan

Correspondence to Dr Mitsuyo Kinjo; kinjomitsuyo@gmail.com

\section{ABSTRACT}

Objective Altered pain sensitivity may affect the outcome of appendicitis in patients with schizophrenia. We aimed to compare the prevalence of perforation in appendicitis between patients with and without schizophrenia.

Design Retrospective cohort study with random matching. Setting A single tertiary medical centre in Japan. Participants From 1985 to 2013, 1821 cases of appendicitis requiring appendectomy were collected. Patients with schizophrenia and a cohort of randomly selected control subjects without schizophrenia who underwent appendectomy were identified.

Primary and secondary outcome measures The primary outcome was the rate of perforated appendicitis in patients with and without schizophrenia. Secondary outcome was the odds of perforated appendicitis by different clinical factors.

Results 62 patients with schizophrenia and randomly sampled 200 non-schizophrenic patients were compared. The prevalence of perforation was $53 \%$ in patients with schizophrenia versus $17 \%$ in controls $(p<0.0001)$. The adjusted OR for perforation were 4.87 ( $95 \% \mathrm{Cl}: 2.33$ to 10.2) for schizophrenia, 3.35 (95\% Cl 1.51 to 7.45$)$ for age $>55$ years and 2.18 ( $95 \% \mathrm{Cl}: 1.12$ to 4.27$)$ for delayed presentation.

Conclusion Appendiceal perforation was more frequent in patients with schizophrenia than controls, which may be partly attributable to delayed presentation and altered responses to pain.

\section{INTRODUCTION}

Early diagnosis of appendicitis is necessary in order to prevent increased surgical morbidity and mortality due to abscess and perforation. ${ }^{1}$ The mortality of appendicitis has been estimated at 2.4 per million and the morbidity has been estimated at 7.7-17.8 per million. ${ }^{23}$

Schizophrenia is a psychiatric disorder consisting of chronic or recurrent psychosis that affects 15 per 100000 persons. The median lifetime morbidity risk for schizophrenia is 7.2 per 1000 persons. ${ }^{4}$ Patients with schizophrenia have often been noted to have decreased perception of pain with altered expression of the emotional response to pain. Pain insensitivity (hypoalgesia) has been described in psychotic disorders since

\section{Strengths and limitations of this study}

This is one of the few retrospective cohort studies with random matching using real-world clinical data to evaluate ruptured appendicitis and its complications among patients with schizophrenia.

- Detailed clinical parameters correlated with surgical outcome during three decades of clinical practice allow us to address the magnitude of schizophrenia on excess adverse outcome independent of other risk factors that may vary over time.

- The retrospective collection of clinical factors is subject to recall bias and other biases.

- We lack data concerning potential differences in the time course of hospital evaluation, and whether the diagnosis of schizophrenia impeded progression of the diagnostic process.

the early 20th century. ${ }^{56}$ Kraepelin noted that patients often become less sensitive to body discomfort: "They endure uncomfortable positions, pricks of needles, injuries, without thinking much of it." ${ }^{6}$ Bleuler observed unusual self-mutilation such as eye enucleation and autocastration and noted the 'complete analgesia' in patients with schizophrenia. ${ }^{5}$ Prior studies indicated diagnostic and surgical delay of somatic problems may often be encountered among patients with schizophrenia. ${ }^{78}$ Patients with schizophrenia who require appendectomy have a high rate of perforation and other adverse outcomes. ${ }^{9}$ Tsay and his colleagues reported that the rate of appendiceal perforation was $46.7 \%$ among schizophrenic cohort and 25.1\% among patients without major psychiatric disorders, suggesting that schizophrenia was associated with a 2.83 times higher risk of having a ruptured appendix. ${ }^{10}$ Cooke et al reported a $66 \%$ perforation rate in a case series of appendicitis in patients with schizophrenia. $^{9}$ Smoking and comorbid conditions such as diabetes and obesity are commonly seen in schizophrenia, and may partly explain the higher rates of appendiceal rupture. The increased rate of complications 
in schizophrenia has been consistent, but the contributions of pain insensitivity and delayed access to medical care have not been defined.

This retrospective cohort study was designed to examine the clinical characteristics of appendicitis in schizophrenic subjects, and to compare the rate of complications to patients without schizophrenia.

\section{METHODS}

\section{Study subjects}

All patients $\geq 18$ years old who had an appendectomy for suspected appendicitis from 1985 to 2013 were collected retrospectively from the record system at Okinawa Chubu Hospital, a tertiary medical centre in Japan. We stratified patients as to whether schizophrenia was present, defined as a diagnosis rendered by a psychiatrist with the confirmation an antipsychotic medication prescription. In no cases were antipsychotic medications prescribed for any control subjects. The diagnosis of schizophrenia corresponded to DSM-4 text revision criteria. Sixty-two patients with schizophrenia and 1759 control subjects without schizophrenia who underwent appendectomy during the observation period were identified. Two hundred patients were randomly selected as controls. This study was approved by the Institutional Ethics Committee of Okinawa Chubu Hospital.

\section{Diagnosis of appendicitis and clinical characteristics}

Data collected included the presenting history and physical examination findings, and the results of CT or ultrasound studies performed prior to surgery. Most appendectomies were performed as open surgery and only a few patients underwent laparoscopic intervention in our cohort. Appendicitis was confirmed by surgical and pathological findings, and the presence of rupture or abscess was noted. Perforated appendicitis was defined either intraoperatively or postoperatively, based on pathological findings. Patient characteristics were recorded including age, gender, smoking, body mass index $\left(\mathrm{kg} / \mathrm{m}^{2}\right)$, history of diabetes and date of appendectomy. Tobacco use was reported by patients and was dichotomised as current versus former/never. Diabetes was self-reported. Clinical characteristics of appendicitis that were collected included abdominal pain, nausea and vomiting. The duration of abdominal symptoms at the time of emergency department (ED) presentation was categorised as either 2 days or longer versus less than 2 days; the duration from ED presentation to operating room was categorised as either 12 hours or longer versus less than 12 hours; vital signs including temperature of $38^{\circ} \mathrm{C}$ or higher and tachycardia $>100$ beats per minute; signs of peritoneal irritation including guarding and rebound tenderness; leucocytosis (white blood cell count $10 \times 10^{9} / \mathrm{L}$ ). Ultrasound or CT findings were recorded, with note of whether appendicitis was reported to be likely. Medication use was ascertained, including antipsychotic drugs (clozapine, olanzapine, risperidone, chlorpromazine hydrochloride, levomepromazine, haloperidol, perospirone and zotepine), benzodiazepine, serotonin selective reuptake inhibitors, tricyclic antidepressants, anticholinergics, corticosteroids and non-steroidal anti-inflammatory drugs.

\section{Statistical analysis}

Sample size calculations were based on a $30 \%$ frequency of perforation in appendicitis in general population and a $66 \%$ frequency of perforated appendicitis in schizophrenia. ${ }^{10}$ Detecting differences of this magnitude with $80 \%$ or $90 \%$ power yielded sample sizes of 29 and 39 patients per group. Controls were selected randomly from all non-schizophrenic patients, using a table of random numbers. Continuous variables were compared using Student's t-test and categorical variable by a two-sided Fisher's exact test, as appropriate; all tests were performed at a $5 \%$ level of significance.

Logistic regression was performed to assess the OR for perforation between schizophrenic and non-schizophrenic patients, controlling for age, gender, body mass index, diabetes, smoking and time of presentation. In sensitivity analysis, a second cohort of age-matched controls was selected from the base non-schizophrenic population, with three controls for each schizophrenic subject, and a conditional logistic regression was performed.

All analyses were performed using $\mathrm{R}$ with no additional packages installed ( $\mathrm{R}$ Foundation for Statistical Computing, Vienna, Austria; https://www.R-project. org/), using the EZR statistical interface, V.2.13.0. The same analysis was replicated using STATA V.14.2.

\section{RESULTS}

Sixty-two cases of appendicitis in patients with schizophrenia were detected, and these cases were compared with 200 controls. Among patients with schizophrenia, the mean age was 43.5 years and $40 \%$ were female; in controls, mean age was 40.2 years and $46 \%$ were female ( $p>0.15$ for both comparisons). Baseline characteristics of both groups are shown in table 1. Compared with controls, the patients with schizophrenia were more likely to be current smokers and have diabetes. Most patients with schizophrenia reported abdominal pain. Consistent with their underlying psychiatric diagnosis, the use of neuroleptics, anxiolytics and anticholinergic drugs was higher in the schizophrenic group, but the use of antidepressants was infrequent in both groups.

Clinical characteristics during the ED presentation are provided in table 2. Compared with controls, patients with schizophrenia were more likely to be febrile and tachycardic, and had a higher frequency of guarding on abdominal examination. Rebound tenderness was common in both groups ( $83 \%$ vs $73 \%, \mathrm{p}=0.16)$. Leucocytosis did not differ between groups. Compared with controls, patients with schizophrenia were significantly more likely to report that the duration of symptoms was $>48$ hours prior to ED 
Table 1 Baseline characteristics of patients with appendicitis, by presence or absence of schizophrenia

\begin{tabular}{lccccc}
\hline & \multicolumn{6}{l}{$\begin{array}{l}\text { Schizophrenia Controls } \\
\text { (n=62) }\end{array}$} & \multicolumn{2}{l}{$\begin{array}{l}\text { (n=200) } \\
\text { p Value }\end{array}$} \\
\hline Age, mean (SD) & 43.5 & 11.6 & 40.2 & 17.1 & 0.17 \\
\hline Female & $\mathrm{n}$ & $\%$ & $\mathrm{n}$ & $\%$ & \\
\hline BMI >25 & 25 & 40 & 92 & 46 & 0.48 \\
\hline Current tobacco & 45 & 74 & 92 & 46 & 0.0002 \\
\hline Diabetes & 8 & 13 & 6 & 3 & 0.006 \\
\hline Medications & & & & & \\
\hline Neuroleptic & 62 & 100 & 0 & 0 & $<0.0001$ \\
\hline Benzodiazepine & 38 & 73 & 4 & 2 & $<0.0001$ \\
\hline Anticholinergic & 45 & 85 & 0 & 0 & $<0.0001$ \\
\hline SSRI & 0 & 0 & 1 & 1 & 1 \\
\hline TCA & 2 & 4 & 1 & 1 & 0.11 \\
\hline NSAID & 2 & 4 & 3 & 2 & 0.28 \\
\hline Glucocorticoids & 0 & 0 & 4 & 2 & 0.58 \\
\hline
\end{tabular}

BMI, body mass index; SSRI, selective serotonin reuptake inhibitors; NSAID, non-steroidal anti-inflammatory drugs; TCA, tricyclic antidepressants.

presentation ( $47 \%$ vs $25 \%, \mathrm{p}=0.002)$. Time from $\mathrm{ED}$ to operating room was not different between groups $(31 \%$ vs $24 \%, \mathrm{p}=0.3)$.

The unadjusted odds of having perforated appendicitis were 2.7 times higher in patients aged 55 or older, 2.99 times higher for delayed presentation and 5.56 times higher in patients with schizophrenia (table 3). Schizophrenia remained the strongest risk factor for perforation, even after adjustment for age, gender, body mass

Table 2 Preoperative findings in patients with and without schizophrenia

\begin{tabular}{|c|c|c|c|}
\hline & Schizophrenia & Controls & \multirow[b]{2}{*}{ p Value } \\
\hline & $\mathbf{N}(\%)$ & $\mathbf{N}(\%)$ & \\
\hline Temp $>38.0^{\circ} \mathrm{C}$ & $25(40)$ & 38 (19) & 0.001 \\
\hline Abdominal pain & $61(98)$ & $199(100)$ & 0.24 \\
\hline Nausea/vomiting & $32(65)$ & $129(70)$ & 0.602 \\
\hline Pulse >100/min & $37(61)$ & $31(16)$ & $<0.0001$ \\
\hline Rebound tenderness & $48(83)$ & $127(73)$ & 0.16 \\
\hline Guarding & $35(65)$ & 37 (32) & 0.0001 \\
\hline WBC $>10000 / \mu \mathrm{L}$ & $48(77)$ & $152(77)$ & 1.0 \\
\hline $\begin{array}{l}\text { Delayed } \\
\text { presentation* }\end{array}$ & $28(47)$ & $50(25)$ & 0.002 \\
\hline Delayed ED to OR† & $18(31)$ & $45(24)$ & 0.3 \\
\hline
\end{tabular}

*Delayed presentation defined as more than 48 hours of symptoms prior to presentation for care.

†Delayed ED to OR defined as $>12$ hours of ED stay prior to appendectomy.

ED, emergency department; OR, operating room; Temp, temperature; WBC, white blood cell. index, diabetes or tobacco use $(\mathrm{OR}=5.42,95 \% \mathrm{CI} 2.66$, 11.1). However, adjusting for delayed presentation in our model attenuated the association between schizophrenia and perforation ( $\mathrm{OR}=4.87,95 \%$ CI 2.33 to 10.2). Among patients with schizophrenia, the odds of perforation did not differ between early versus delayed presentation $(53 \%$ vs $57 \%, \mathrm{p}=0.8$ ). Once diagnosed, patients with schizophrenia were more likely to have longer hospital lengths of stay, more postoperative complications and unfavourable histopathology (table 4).

The rate of ruptured appendicitis did not differ before and after the year 2000 (58\% vs 52\%, p=0.79 in schizophrenia, $19 \%$ vs $12 \%, \mathrm{p}=0.7$ in controls), when CT scan for the diagnosis of appendicitis became more readily available, with better image quality.

\section{Sensitivity analysis}

In our sensitivity analysis using a cohort of matched controls and adjusting for the same demographic and clinical factors (including time of presentation), age $>55$ was no longer a risk for perforation $(\mathrm{OR}=0.77,95 \% \mathrm{CI}$ $0.14,4.22)$. However, schizophrenia remained a significant risk factor $(\mathrm{OR}=2.96,95 \%$ CI $1.39,6.27)$ as well as delayed presentation $(\mathrm{OR}=4.46,95 \%$ CI $2.30,8.64)$.

\section{DISCUSSION}

This retrospective cohort study described the features of appendicitis in patients with schizophrenia and demonstrated that patients with schizophrenia had substantially greater odds of having perforation. Increased risk at the time of operation was independent of known risk factors such as age, smoking or diabetes, compared with non-schizophrenics. Most patients with schizophrenia reported classic abdominal symptoms. This study provided insights into the poor outcomes experienced by this vulnerable patient group.

Contrary to the notion that patients with schizophrenia are insensitive to pain and somatic sensation, ${ }^{11}{ }^{12}$ the present study demonstrated that most patients with schizophrenia presented with classic symptoms of appendicitis including abdominal pain as reported previously. ${ }^{9}$ In our study, some clinical signs such as fever, tachycardia and abdominal guarding were more pronounced in schizophrenics. About half $(47 \%)$ of the patients with schizophrenia took more than 2 days to access hospital care after the onset of abdominal symptoms, so delay in seeking medical attention may partly explain the discrepant clinical presentation and higher incidence of perforated appendicitis in schizophrenia.

Diabetes and tobacco use have been associated with increased risk of perforation in appendicitis. ${ }^{13-15}$ Our findings are concordant with other studies in which patients with schizophrenia are more likely to be overweight, diabetic and less likely to adhere to a healthy lifestyle. ${ }^{16}$ Bushe reported the prevalence of diabetes was approximately $15 \%$ in a sample of patients with schizophrenia. ${ }^{17}$ In another study, $65 \%-79 \%$ of patients with 
Table 3 Odds of perforated appendicitis by clinical factors

\begin{tabular}{|c|c|c|}
\hline Characteristics & Unadjusted OR (95\% Cl) & Fully adjusted OR $(95 \% \mathrm{Cl})^{*}$ \\
\hline Age $>55$ & 2.7 (1.42 to 5.23$)$ & 3.35 (1.51 to 7.45$)$ \\
\hline Female sex & 1.09 (0.63 to 1.91$)$ & $1.16(0.60$ to 2.23$)$ \\
\hline Diabetes mellitus & 2.30 (0.77 to 6.89$)$ & 0.96 (0.27 to 3.39$)$ \\
\hline Body mass index $>25$ & 1.57 (0.87 to 2.72$)$ & 1.41 (0.71 to 2.81$)$ \\
\hline Current smoker & 1.54 (0.87 to 2.72$)$ & 1.23 (0.62 to 2.46$)$ \\
\hline Schizophrenia & 5.56 (2.99 to 10.3$)$ & 4.87 (2.33 to 10.2$)$ \\
\hline \multicolumn{3}{|l|}{ Time of presentation } \\
\hline$>48$ hours & 2.99 (1.66 to 5.63$)$ & $2.18(1.12$ to 4.27$)$ \\
\hline
\end{tabular}

*Age, gender, diabetes, smoking, body mass index, schizophrenia and time of presentation.

schizophrenia were reported to be smokers. ${ }^{18}$ Despite this, our data showed that adjustment for traditional risk factors did not attenuate the association of schizophrenia with increased appendiceal rupture. Schizophrenia was more strongly associated with ruptured appendicitis than any other variable we evaluated.

The increased risk of perforation in schizophrenia was attenuated when the model was adjusted for delayed presentation, suggesting that patients with schizophrenia may be systematically less likely to seek medical care in response to abdominal pain. Delayed presentation has been associated with the risk of perforation in other populations. ${ }^{19}$ Nearly all of our patients with schizophrenia reported abdominal pain, contradicting the notion that they do not experience pain. However, patients with schizophrenia may have abnormal perception and reporting of pain, which may be related to

Table 4 Characteristics of perforated appendicitis and hospitalisation, by presence or absence of schizophrenia

\begin{tabular}{|c|c|c|c|}
\hline & Schizophrenia & Controls & \multirow{2}{*}{ p Value } \\
\hline & $\mathbf{N}(\%)$ & $\mathbf{N}(\%)$ & \\
\hline Perforation & $33(53)$ & $34(17)$ & $<0.0001$ \\
\hline $\begin{array}{l}\text { Hospital length of stay } \\
>7 \text { days }\end{array}$ & $43(69)$ & $72(36)$ & $<0.0001$ \\
\hline Death & $0(0)$ & $1(1)$ & 1 \\
\hline $\begin{array}{l}\text { Wound healing by } \\
\text { secondary intention }\end{array}$ & $35(56)$ & $44(22)$ & $<0.0001$ \\
\hline Wound infection & $0(0)$ & $6(3)$ & 0.34 \\
\hline $\begin{array}{l}\text { Appendiceal tear at } \\
\text { operation }\end{array}$ & $2(3)$ & $8(4)$ & 1 \\
\hline Suppurative ascites & $1(1)$ & $2(1)$ & 0.56 \\
\hline $\begin{array}{l}\text { Intra-abdominal } \\
\text { abscess }\end{array}$ & $19(31)$ & $14(7)$ & $<0.0001$ \\
\hline Bacteraemia/sepsis & $5(8)$ & $5(3)$ & 0.06 \\
\hline Reoperation & $3(5)$ & $0(0)$ & 0.01 \\
\hline Respiratory arrest & $1(2)$ & $1(1)$ & 0.42 \\
\hline $\begin{array}{l}\text { Gangrenous or } \\
\text { necrotic appendicitis }\end{array}$ & $27(43)$ & $29(15)$ & $<0.0001$ \\
\hline
\end{tabular}

medications or the underlying psychiatric disorder. ${ }^{20}$ Delay in seeking medical attention may be partially attributable to altered pain sensitivity in schizophrenia. Our data contrast with those of Marchand, who reported that $37 \%$ of schizophrenia patients with appendicitis reported no pain. ${ }^{21}$ Lack of insurance and financial restrictions are minimised under the universal healthcare system in Japan, which confers support for living costs and medical expenditures for patients diagnosed with schizophrenia. However, our data do not permit us to speculate on non-financial factors such as perceptions of stigma in the healthcare setting.

Once hospitalised, patients with schizophrenia with appendicitis had more unfavourable surgical findings, and had poorer outcomes with increased complications. Our data are consistent with those of Daumit $e t$ al, who noted that patients with schizophrenia have a greater than twofold risk of major avoidable inhospital complications. ${ }^{22}$ Patients with schizophrenia suffered from more medical complications and longer lengths of stay, partially reflecting later presentation with more advanced inflammatory deterioration of the appendix and surrounding tissues. Regardless of the timing of presentation, however, our data indicate that there is still substantial excess risk of perforation associated with schizophrenia. We cannot rule out the possibility that the pathophysiology of appendicitis may be different in patients with schizophrenia, due to alterations in the microbiome or altered inflammatory responses. ${ }^{11} 12$

Our data do not permit us to draw conclusions about the associations between antipsychotic medication use, or severity of schizophrenia, and appendiceal perforation. Patients with schizophrenia tended to have more severe psychiatric symptoms in the inpatient setting, and often required increased medications. However, our results show that the rate of perforation did not differ between hospitalised and non-hospitalised patients with schizophrenia ( $50 \%$ vs $71 \% \mathrm{p}=0.11$ ), suggesting that schizophrenia itself, rather than the medications for schizophrenia, is a risk factor for perforated appendicitis.

There are several strengths in this study. First, this is one of a few cohort studies that has evaluated ruptured 
appendicitis and its complications among patients with schizophrenia. Second, detailed clinical parameters with surgical outcome during three decades of clinical practice allow us to address the magnitude of schizophrenia on excess adverse outcome independent of other risk factors that may vary over time.

Several limitations merit discussion. The retrospective collection of risk factors is subject to recall bias and other biases. However, our data showed proportions of current smokers and diabetes in schizophrenia that were similar to other studies. We did not have data concerning potential differences in dietary habits, the time course of hospital evaluation, and whether the diagnosis of schizophrenia impeded progression of the diagnostic process. We also lacked sufficient data to define the effects of $r$ antipsychotics, antidepressants or benzodiazepines and other medications on pain sensitivity.

In conclusion, patients with schizophrenia are at high risk for perforation and other complications of appendicitis, due in part to delayed presentation with more advanced inflammation. Further work may reveal strategies to improve outcomes in these vulnerable patients.

Acknowledgements Koichiro Gibo, Yoshihiko Raita and Kensuke Nakanishi for assistance with data analysis. Eitaro Jiroku and Naoko Hentona for data collection. Katsumi Oyafuso, Shinichiro Ueda, Tsuyoshi Morimoto and Mio Sakuma for advice about study design, as well as Lisa M Rucker, Thomas Lynn Hurt and Lawrence Tierney for advice on manuscript content.

Contributors YN substantially contributed to the conception or design of the work, or the acquisition, analysis or interpretation of data. RLM provided substantial contributions to the conception or design of the work, or the acquisition, analysis or interpretation of data, and revised it critically for important intellectual content. MK drafted the work and critically revised for important intellectual content.

\section{Competing interests None declared.}

Patient consent Detail has been removed from this case description/these case descriptions to ensure anonymity. The editors and reviewers have seen the detailed information available and are satisfied that the information backs up the case the authors are making.

Provenance and peer review Not commissioned; externally peer reviewed. Data sharing statement No additional data are available.

Open Access This is an Open Access article distributed in accordance with the Creative Commons Attribution Non Commercial (CC BY-NC 4.0) license, which permits others to distribute, remix, adapt, build upon this work non-commercially, and license their derivative works on different terms, provided the original work is properly cited and the use is non-commercial. See: http://creativecommons.org/ licenses/by-nc/4.0/ (c) Article author(s) (or their employer(s) unless otherwise stated in the text of the article) 2017. All rights reserved. No commercial use is permitted unless otherwise expressly granted.

\section{REFERENCES}

1. Von Titte SN, McCabe CJ, Ottinger LW. Delayed appendectomy for appendicitis: causes and consequences. Am J Emerg Med 1996;14:620-2 (published Online First: 1996/11/01).

2. Lee SL, Ho HS. Acute appendicitis: is there a difference between children and adults? Am Surg 2006;72:409-13.

3. Pieper R, Kager L, Näsman P. Acute appendicitis: a clinical study of 1018 cases of emergency appendectomy. Acta Chir Scand 1982;148:51-62 (published Online First: 2008/05/16).

4. McGrath J, Saha S, Chant D, et al. Schizophrenia: a concise overview of incidence, prevalence, and mortality. Epidemiol Rev 2008;30:67-76.

5. Bleuler E. Dementia praecox or the group of schizophrenias, 1950.

6. Kraepelin E. Dementia praecox and paraphrenia: Krieger Publishing Company, 1971.

7. Bickerstaff LK, Harris SC, Leggett RS, et al. Pain insensitivity in schizophrenic patients. A surgical dilemma. Arch Surg 1988;123:49-51.

8. Farasatpour M, Janardhan R, Williams CD, et al. Breast cancer in patients with schizophrenia. Am J Surg 2013;206:798-804.

9. Cooke BK, Magas LT, Virgo KS, et al. Appendectomy for appendicitis in patients with schizophrenia. Am J Surg 2007;193:41-8 (published Online First: 2006/12/26).

10. Tsay JH, Lee CH, Hsu YJ, et al. Disparities in appendicitis rupture rate among mentally ill patients. BMC Public Health 2007;7:331.

11. Potvin S, Stip E, Sepehry AA, et al. Inflammatory cytokine alterations in schizophrenia: a systematic quantitative review. Biol Psychiatry 2008;63:801-8.

12. Fillman SG, Cloonan N, Catts VS, et al. Increased inflammatory markers identified in the dorsolateral prefrontal cortex of individuals with schizophrenia. Mol Psychiatry 2013;18:206-14.

13. Sadr Azodi O, Lindström D, Adami J, et al. Impact of body mass index and tobacco smoking on outcome after open appendicectomy. Br J Surg 2008;95:751-7.

14. Tsai SH, Hsu CW, Chen SC, et al. Complicated acute appendicitis in diabetic patients. Am J Surg 2008;196:34-9.

15. Buchman TG, Zuidema GD. Reasons for delay of the diagnosis of acute appendicitis. Surg Gynecol Obstet 1984;158:260-6.

16. Dickerson FB, Brown $\mathrm{CH}$, Kreyenbuhl JA, et al. Obesity among individuals with serious mental illness. Acta Psychiatr Scand 2006;113:306-13.

17. Bushe C, Holt R. Prevalence of diabetes and impaired glucose tolerance in patients with schizophrenia. Br J Psychiatry Suppl 2004;47:s67-s71.

18. McCreadie RG. Scottish Comorbidity Study Group. Use of drugs, alcohol and tobacco by people with schizophrenia: case-control study. Br J Psychiatry 2002;181:321-5.

19. Bickell NA, Aufses AH, Rojas M, et al. How time affects the risk of rupture in appendicitis. J Am Coll Surg 2006;202:401-6.

20. Singh MK, Giles LL, Nasrallah HA. Pain insensitivity in schizophrenia: trait or state marker? J Psychiatr Pract 2006;12:90-102.

21. Marchand WE. Occurrence of painless myocardial infarction in psychotic patients. N Engl J Med 1955;253:51-5.

22. Daumit GL, Pronovost PJ, Anthony CB, et al. Adverse events during medical and surgical hospitalizations for persons with schizophrenia. Arch Gen Psychiatry 2006;63:267-72. 